\title{
Biological constraints on instrumental and classical conditioning: Retrospect and prospect
}

\author{
MICHAEL DOMJAN \\ University of Texas, Austin, Texas \\ and \\ BENNETT G. GALEF, JR. \\ McMaster University, Hamilton, Ontario, Canada
}

\begin{abstract}
The adequacy of traditional approaches to the study of animal learning to account fully for learning phenomena has been seriously questioned during the past decade. Critics of traditional analyses advocated a biological orientation to the interpretation of associative processes and introduced a variety of concepts intended to provide a new framework for the study of animal learning. This promise of a reorientation of the field has not been realized. The concepts of biological constraints, adaptive specializations, and situation specificity of learning have had a less profound influence on the general process approach to instrumental and classical conditioning than anticipated. The present paper makes explicit the conceptual bases of the original biological approaches to learning, identifies reasons why they failed to change fundamentally the study of instrumental and classical conditioning, and proposes an alternative approach to the use of ecological and evolutionary principles in studies of conditioning. We suggest a renewed comparative approach to the study of learning phenomena that avoids many of the difficulties inherent in earlier formulations by providing (1) a strategy for the discovery of adaptive specializations in learning, (2) an ecological framework for the discussion of these adaptive specializations, and (3) a renewed emphasis on the study of species differences in learning.
\end{abstract}

Investigators of animal learning have traditionally assumed that general laws could be discovered through intensive study of learning in arbitrary situations. This belief was seriously called into question during the last decade (Bolles, 1970; Hinde \& StevensonHinde, 1973; Rozin \& Kalat, 1971; Seligman, 1970; Seligman \& Hager, 1972; Shettleworth, 1972). Criticism of the traditional approach was stimulated by observations of learning phenomena that were contrary to widely espoused general principles of association learning and that appeared to illustrate biological constraints on instrumental and classical conditioning. It was frequently suggested that there was a need for a new framework for the study of animal learning integrated with considerations of ecological adaptation and evolutionary history.

Within a few years, biological constraints were

An earlier version of this paper was presented by $M$. Domjan as an invited paper at the 44th Annual Meeting of the Midwest Psychological Association, Minneapolis, 1982. Preparation of the manuscript was supported by grants from the National Science and Engineering Research Council of Canada and the McMaster University Research Board to B. G. Galef, Jr. Requests for reprints should be addressed to M. Domjan, Department of Psychology, University of Texas, Austin, Texas 78712. treated as a major problem in animal learning (e.g., Adams, 1976; Bolles, 1975; Hall, 1976; Houston, 1976; Morgan \& King, 1975; Schwartz, 1978; Tarpy \& Mayer, 1978). Extensive discussion of the issue suggested that a revolution in the study of learning was in the making. The expectation was that investigators would be compelled to abandon traditional approaches to the study of instrumental and classical conditioning in favor of more biologically oriented strategies sensitive to the possibility that specialized mechanisms had evolved to facilitate learning in biologically important situations.

Although such concepts as biological constraints and adaptive specializations had significant influence in other areas, consideration of recent major developments in the study of animal learning suggests that the biological revolution that seemed imminent a decade ago has not occurred. Few new instances of biological constraints on instrumental and classical conditioning have been discovered, and most students of conditioning continue to emphasize general, rather than specialized, mechanisms of association formation (e.g., Dickinson, 1980; Mackintosh, 1975; Pearce \& Hall, 1980; Rachlin, Battalio, Kagel, \& Green, 1981; Rescorla \& Holland, 
1982; Wagner, 1982). The purpose of the present paper is to make explicit reasons why biological constraint formulations have not stimulated fundamental changes in the study of conditioning phenomena, and to propose a new approach to the investigation of ecological and evolutionary factors in conditioning and learning. We will show that perceived weaknesses inherent in conceptions of biological constraints prevented them from having greater impact. To remedy these weaknesses, we will propose an emphasis on ecologically oriented comparative studies of learning.

\section{CONSTRAINTS ON LEARNING}

Biologically oriented arguments about the inadequacy of traditional general process learning theory were stated in various ways. Some authors emphasized the evolution of specialized learning mechanisms that enabled animals to cope especially well with particular challenges to survival such as predatory attack or dietary insufficiency (e.g., Bolles, 1970; Rozin \& Kalat, 1971). Further interest in seemingly specialized learning abilities was stimulated by numerous other instances in which learning was difficult to obtain, or did not occur at all, despite adherence to procedures expected to produce learning (e.g., Breland \& Breland, 1961). Such failures of learning, contrary to predictions of general process theory, challenged conventional thinking at least as much as, if not more than, examples of especially efficient learning. Emphasis on failures of learning in particular situations was captured in the phrase "biological constraints on learning." This phrase (and its synonyms) has been used extensively in biologically oriented discussions about the inadequacy of general process learning theory. For example, it was used as the title of important books, review papers, and textbook chapters on the topic (e.g., Hinde \& Stevenson-Hinde, 1973; Houston, 1976; Rachlin, 1976; Schwartz, 1978; Seligman \& Hager, 1972; Shettleworth, 1972). Because of the extensive use of the phrase "biological constraints," and its possible impact on conceptualizations, we will consider implications of the phrase in trying to analyze why biological concepts have not had greater influence on the study of associative learning.

A constraint on a phenomenon is a limitation on or boundary condition for its occurrence. Scientific investigations invariably reveal circumstances in which a phenomenon of interest occurs and other circumstances in which it does not take place. This is as true in studies of learning as in studies of other aspects of nature. Traditional investigations of instrumental and classical conditioning have documented numerous constraints on the formation of associations: for example, the interval between conditioned and unconditioned stimuli (CSs and USs), the intensity and novelty of conditioned and uncon- ditioned stimuli, and the extent to which unconditioned stimuli are surprising. Such constraints on association formation constitute our basic knowledge about learning from which extant general theories have been constructed. It is clear, however, that these sorts of constraints are not those generally referred to as "biological constraints" on learning.

\section{Conceptual Foundations of Biological Constraints}

At least four concepts have been employed in identifying biological constraint phenomena. These concepts are not mutually exclusive, and different theorists have emphasized different aspects of them (see Johnston, 1981, and ensuing discussion). Therefore, our description of the concepts should not be interpreted as reflecting a uniformity of viewpoints about biological constraints.

Exceptions to general process learning theory. The primary impetus for discussions about biological constraints on learning was the discovery of learning phenomena that were contrary to known laws of instrumental and classical conditioning. For many, such inconsistency with traditional learning theory in itself defined instances of biological constraints. Emphasis on constraint phenomena as exceptions to known principles of behavior is evident, for example, in the title used by Breland and Breland (1961) for their classic discussion of biological constraints on instrumental conditioning, "The misbehavior of organisms." This working definition is also evident in many textbook accounts that present a discussion of constraints on learning as exceptions to conventional principles of classical and instrumental conditioning (e.g., Rachlin, 1976; Schwartz, 1978).

Some authors did not specify aspects of traditional learning theory that were violated by biological constraints. Others discussed biological constraints as violations of the principle of equipotentiality (Seligman, 1970; Seligman \& Hager, 1972; Shettleworth, 1972). The equipotentiality principle, which has been treated as fundamental to generalprocess learning theories, assumes that mechanisms of learning are independent of the particular combinations of cues, responses, and reinforcers involved in a learning situation. Limitations on learning due to factors such as the CS-US interval or CS and US intensity were not regarded as biological constraints because such limitations were presumed to be independent of particular conditioned and unconditioned stimuli employed.

Situation specificity of learning. Instances of learning that violate the equipotentiality principle do so because they occur only in situations that contain particular cues, responses, or reinforcers, or special combinations of these elements. Situation specificity was fundamental to all discussions of biological constraints. Seligman (1970) and Shettleworth (1972) focused on situation specificity as disproof of the 
principle of equipotentiality. Bolles (1970) discussed differences in avoidance learning as a function of the instrumental response required in various avoidance conditioning situations. Rozin and Kalat (1971) discussed learning in food-selection situations as distinct from learning in other circumstances. Hinde (1973) similarly described instances of learning that appeared to be specific to particular situations as illustrating constraint phenomena.

Adaptive specializations of learning. Many phenomena discussed as instances of biological constraints appear to be adaptations to particular challenges to survival. Rozin and Kalat (1971) emphasized that special features of problems animals encounter in accomplishing certain critical activities (e.g., selecting nutritious foods) have led to the evolution of specialized learning processes. They assumed not only that certain instances of learning may have unique adaptive value, but also that such instances are mediated by specialized mechanisms. However, Rozin and Kalat did not regard every instance of learning as reflecting specialized adaptations. They acknowledged that some general learning mechanisms may exist, reflecting basic properties of the nervous system, common problems faced by various species, and/or the costs of evolving specializations.

Experience-independent associative bias. Some researchers used the term "constraint on learning" or "biological constraint" to refer to an experienceindependent associative bias, that is, an inherited tendency to learn some relationships much more readily or faster than others (e.g., Schwartz, 1978). According to this usage, the feature distinguishing biological constraints on learning from other limitations is that they do not result from past experience. This qualification implies a strong distinction between experience-dependent and experience-independent aspects of behavior, which is often difficult to maintain (e.g., Lehrman, 1970). Available evidence also does not permit the conclusion that frequently discussed examples of biological constraints on learning are any more independent of past experience than many traditional limitations on learning. Some traditional limitations on learning, such as familiarity with the CS or US, clearly result from a subject's past experience. However, other long-accepted boundaries of learning, such as effects of the magnitude or intensity of the reinforcer or effects of the CS-US interval, cannot be easily interpreted as experience dependent.

\section{INADEQUATE PROGRAMMATIC IMPLICATIONS OF BIOLOGICAL CONSTRAINTS}

The study of biological constraints on instrumental and classical conditioning has not become a sub- stantive area within the field of animal learning because, for traditional investigators, ideas fundamental to biological constraints did not suggest productive empirical and theoretical approaches to the study of association learning. In general, biological constraint concepts did not suggest distinctive methods for discovery of new instances of biological constraints and did not lead to the formulation of successful frameworks for systematizing constraint phenomena. Furthermore, identified examples of constraints on association learning were easily assimilated into revisions of general process theory, thereby eliminating many of them from deserving special consideration.

\section{Methods for Discovery of New \\ Biological Constraints}

Exceptions to general process theory. If the primary identifying feature of biological constraints is inconsistency with traditional theories of learning, then discovery of new instances of biological constraints requires discovery of empirical challenges to general process theories. To find an exception to a rule, implications of that rule must be tested with the hope that such tests will reveal unpredicted outcomes. Such activity makes the search for instances of biological constraints no different from studies of learning arising from traditional approaches. Investigators primarily interested in general process learning theory test various theoretical predictions in an effort to discover violations of expected results. Emphasis on exceptions to traditional theories of learning in discussions of biological constraints did not require departure from this conventional approach in attempts to discover new constraint phenomena.

Situation specificity of learning. The concept of situation specificity, like emphasis on exceptions to the rule, failed to provide a systematic method for discovery of new biological constraint phenomena. To demonstrate situation specificity, one must show that learning proceeds differently in two or more circumstances. However, the concept of situation specificity does not dictate which circumstances should be chosen for comparison. This makes the choice largely arbitrary. In consequence, studies of situation specificity of learning frequently involve arbitrary, rather than biologically oriented, comparisons. Consider, for example, the selective aversion conditioning effect first demonstrated by Garcia and Koelling (1966): when rats are made sick, they learn an aversion to taste but not to audiovisual cues; conversely, when rats receive footshock, they learn an aversion to audiovisual cues but not to taste. This widely cited example of a biological constraint on learning represents the arbitrary juxtaposition of two learning situations, fear and poison-avoidance conditioning. We do not know of any biologically based 
hypotheses that encourage such a comparison. The rationale for such experiments rests solely with general process approaches to the study of learning. Because general process approaches assume that the mechanisms of learning are similar in all circumstances, comparisons of association learning with disparate and biologically unrelated pairs of stimuli are justified as tests of general process theory.

A further difficulty of the situation-specificity concept for discovery of new biological constraints is that it presupposes that situations are easily distinguished. Categorization of situations may be more difficult to accomplish than is apparent. How can we tell where one situation ends and another begins, or whether two types of learning exemplify learning in different situations rather than parametric variations within a single situation? Welker and Wheatley (1977), for example, observed that in a conditioned suppression procedure increased illumination was easier to condition as a fear signal than was decreased illumination. Is this difference in conditioned stimuli sufficient to define fear conditioning to increased and decreased illumination as constituting two different situations?

Implicit in the concept of situation specificity as employed in discussions of biological constraints is the idea that different mechanisms of learning are involved in different situations. Two situations are considered to be different if learning in the two cases is mediated by different processes. However, this usage is circular. Nothing is gained by defining a constraint on learning as a situation-specific instance of learning if differences in situations can be identified only by differences in learning mechanisms.

Adaptive specialization of learning. The concept of adaptive specializations shares some features of conceptions of biological constraints as exceptions to general process theory and as situation-specific instances of learning. Because adaptive specializations are assumed to occur against a background of general mechanisms of learning, adaptive specializations are exceptions to such general processes. In addition, to distinguish adaptive specializations from general adaptive mechanisms of learning, one has to assume that adaptive specializations are specific to particular situations. Despite these characteristics, the concept of adaptive specializations provides a more distinctive strategy for discovering new instances of specialized learning than do other biological constraint concepts. Rozin and Kalat (1971) suggested that consideration of special circumstances animals encounter in their natural habitat may suggest specialized learning abilities that have evolved to deal with these problems. For example, the existence of toxins with delayed effects in the potential food sources of a particular species may be used to predict the existence of mechanisms enabling that species to learn aversions to food over long delays between in- gestion and subsequent malaise. The suggestion that information about special problems confronting particular animals can be profitably used to search for new learning phenomena is certainly valuable. However, without elaboration, this approach to the discovery of new instances of specialized learning is rather informal and has been rarely used since it was proposed.

\section{Failure to Systematize Information About Blological Constraints}

A further reason why biological constraint concepts did not stimulate fundamental changes in the study of animal learning is that they did not lead to a successful theoretical framework for systematizing knowledge about constraint phenomena. There is no reason to believe that constraints on instrumental and classical conditioning identified as exceptions to traditional principles of learning will have other common attributes. Similarly, situation-specific instances of learning and adaptive specializations may be produced by a large variety of mechanisms.

Preparedness. Perhaps the best known attempt to systematize information about biological constraints on learning is the concept of preparedness proposed by Seligman (1970). Preparedness is defined as "the degree of input necessary to produce a specified output" in a learning experiment (Seligman, 1970, p. 407). The fewer the number of acquisition trials needed, for example, the greater the degree of preparedness of the organism to learn a particular task. It is difficult to see how this or any other measure of preparedness can be used to systematize learning in diverse situations. For example, both taste-aversion learning in rats and language acquisition in children have been discussed as illustrating highly prepared forms of learning (Seligman \& Hager, 1972). However, the marked differences in stimuli, responses, and organisms involved in these types of learning would seem to preclude finding a single measure of acquisition that could be applied meaningfully to both cases.

Another weakness of the attempt to systematize information about biological constraints in terms of the concept of preparedness is that various forms of learning, similar in their degree of preparedness, may not share other characteristics. Seligman and Hager (1972) expressed the hope that differences in the degree of preparedness as measured by one index of learning would be accompanied by differences in other characteristics. This has not turned out to be the case. Association of a taste with subsequent illness (taste-aversion learning), for example, was considered to be a highly prepared form of learning because it occurs in only one trial and does not require a close temporal relationship between taste and illness. These characteristics of taste-aversion learning were assumed to be accompanied by other features that 
also set it apart from types of learning that occur more slowly. Contrary to this prediction, recent research has indicated that taste-aversion learning is similar to more conventional types of learning in most qualitative properties (see reviews by Domjan, 1980, Logue, 1979, and Spiker, 1977).

Situation specificity. Other efforts to systematize examples of biological constraints on learning have similarly turned out to be uninformative about underlying mechanism. Shettleworth (1972) classified constraints on learning in terms of whether they resulted from particular cues, responses, or reinforcers (or combinations of these) that were used in a learning situation. However, subsequent work has shown that each of these categories of constraint can be produced by a variety of mechanisms (Domjan, 1983). For example, constraints on the instrumental conditioning of various responses may arise because of conditioned and unconditioned motivational states created by the instrumental procedure (e.g., Shettleworth, 1975), because of discriminability of the various responses (e.g., Morgan \& Nicholas, 1979), or because of the presence or absence of supporting stimulation (e.g., Pearce, Colwill, \& Hall, 1978).

Adaptive functions of learning. The concept of adaptive specializations encourages systematizing instances of biological constraints in terms of particular adaptive functions of learning. In the original use of this concept in discussions of biological constraints, many claims of adaptive function were post hoc. For example, Rozin and Kalat (1971) discussed poison avoidance learning as an adaptive specialization. One of the prominent features of poison-avoidance learning is that rats will tolerate very long intervals between a novel flavor and subsequent illness and still learn aversions to the flavor (e.g., Garcia, Ervin, \& Koelling, 1966). However, little direct evidence is available that rats encounter palatable but toxic foods in their natural habitat, that such toxins have effects delayed by many minutes or hours, or that the resultant illness is readily associated with ingestion. For all we know, rats undisturbed by man usually become ill as the result of bacterial, viral, or parasitic infection. The formation of food aversions on the basis of such illness may be, on average, counterproductive.

Use of the concept of adaptive specializations also did not lead to a successful framework for systematizing information about biological constraints, because proponents of this concept hypothesized that adaptive specializations were mediated by specialized learning mechanisms (Rozin \& Kalat, 1971). The adaptive functions of learning have been considered more recently by Hollis (1982) and Shettleworth (1982), who pointed out that concern about adaptive functions of learning was distinct from concern about underlying mechanism (Tinbergen, 1963). The same underlying mechanism may be responsible (with appropriate variations in parameters) for forms of learning that have very different adaptive functions. Conversely, different mechanisms may contribute to instances of learning that have similar adaptive functions. Thus, adaptive specializations in function are not necessarily the result of specialized mechanisms. Recent research on poison-avoidance learning, for example, illustrates how this apparently specialized form of learning is largely the product of general learning mechanisms (e.g., Domjan, 1980, 1983; Logue, 1979).

\section{Assimilation of Biological Constraints Into a Revised General Process Learning Theory}

Perhaps the most important reason why biological constraint concepts have not created a revolution in the study of instrumental and classical conditioning is that many phenomena initially considered to be outside the scope of general learning theory have been incorporated into revisions of such theory. Among the earliest advocates of this approach to biological constraint phenomena were Revusky (1971), Rescorla and Holland (1976), and LoLordo (1979). Assimilation of biological constraints into revised general theories of learning has eliminated many phenomena as deserving special attention and has contributed to the demise of biological constraints as a special area of investigation.

Situation-specific instances of learning are especially susceptible to assimilation into general process theory. Learning situations basically differ in terms of the cues, responses, and reinforcers they contain and how these are arranged. The basic element of general process learning theory are also cues, responses, and reinforcers. If general process theory cannot accommodate some new instances of situation specificity, it is frequently the case that such weakness can be remedied by appropriate modifications of, or additions to, the general principles. For example, in response to evidence that associations may be more easily formed between certain combinations of conditioned and unconditioned stimuli than others (e.g., Garcia \& Koelling, 1966), some have proposed the addition of a stimulus relevance or belongingness principle to general process learning theory (e.g., Revusky, 1971). Others have suggested the addition of stimulus similarity as a factor in Pavlovian conditioning (e.g., Rescorla \& Furrow, 1977; Testa \& Ternes, 1977).

Other instances of biological constraints on learning are also consistent with revised general views of learning. Recent research on "misbehavior" in depositing tokens for positive reinforcement (Timberlake, Wahl, \& King, 1982), constraints on the topography of positively reinforced behavior (Shettleworth, 1975), constraints on punishment (Shettleworth, 1978), constraints on avoidance learning (Crawford 
\& Masterson, 1978), long-delay learning (D'Amato \& Buckiewicz, 1980; Lieberman, McIntosh, \& Thomas, 1979), and potentiation in classical conditioning (Pearce, Nicholas, \& Dickinson, 1981) suggest that each of these phenomena may be the product of general mechanisms of learning (see Domjan, 1983).

\section{THE FUTURE OF BIOLOGICAL APPROACHIS TO THE STUDY OF LEARNING}

The foregoing discussion suggests numerous reasons why consideration of biological constraints on instrumental and classical conditioning have not produced fundamental changes in the study of learning. Where should we go from here? Should we consider the failures of earlier conceptions of biological constraints a triumph for general process learning theory and put the entire matter behind us? Or, should we make a new start to try to integrate the study of learning with biological considerations?

\section{Is the Study of Biological Constraints on Learning Worth Pursuing?}

Although biological constraints have not revolutionized the study of association learning, investigations of constraint phenomena did contribute significant empirical findings to the understanding of learning processes (see Domjan, 1983, for a recent review). Studies of constraints have increased awareness of the potential importance of a number of variables in positive reinforcement procedures in addition to the response-reinforcer contingency. These variables include the classical conditioning of manipulanda that signal the presentation of the reinforcer (see Timberlake et al., 1982), limitations in the behavioral repertoire caused by unconditioned or conditioned motivational states involved in reinforcement (e.g., Shettleworth, 1975), discriminability of the instrumental behavior (Morgan \& Nicholas, 1979), supporting stimulation for the instrumental behavior (Pearce, Colwill, \& Hall, 1978), and innate behavioral sequences to which the instrumental response may belong (Annable \& Wearden, 1979). Studies of constraints on aversive conditioning have emphasized both the importance of responses elicited by the aversive stimulus and the role of particular stimuli that serve as warning and safety signals in avoidance procedures (Bolles, 1970; Crawford \& Masterson, 1978; Jacobs \& LoLordo, 1977, 1980; Shettleworth, 1978). Investigations of cue-consequence specificity in classical conditioning have highlighted the importance of orientation to the conditioned stimuli (Gillette, Martin, \& Bellingham, 1980), similarity between the conditioned and unconditioned stimuli (e.g., Rescorla \& Gillan, 1980; Testa, 1975), and temporal relationships of CS- and US- induced sensations (Krane \& Wagner, 1975). Studies of longdelay learning have illustrated the importance of in- terfering stimuli during a CS-US interval (Lett, 1975; Revusky, 1971), of marking with a salient stimulus the response to be conditioned (Lieberman et al., 1979), and of the distinction between affective and instrumental responses (D'Amato \& Safarjan, 1981).

Perhaps most importantly, the study of biological constraints called attention to a fundamental issue in the interpretation of the processes underlying associative learning. Introduction of terms such as "preparedness," "adaptive specialization," "speciesspecific defense reactions," and "situation specificity" into discussions of learning in the early 1970s either explicitly or implicitly promoted awareness of the possibility that ecological pressures might result in the evolution of specialized associative processes facilitating learning of interevent associations of particular importance in promoting individual fitness. This hypothesizing of the existence of specialized learning mechanisms, idiosyncratic to particular species, contrasted sharply with the previously prevailing view that mechanisms of associative learning were uniform in vertebrates. The question of the existence of specialized learning mechanisms is important because it bears directly on the usefulness of the general process approach that has characterized the study of animal learning since its inception.

\section{Alternative New Directions}

We are not the first to suggest that what we have characterized as the biological-constraints approach failed to provide theoretical or methodological structures for addressing the question of the existence of specialized associative learning processes and, therefore, failed to provide an appropriate framework for the integration of learning theory with more biologically oriented approaches to the study of behavioral plasticity. In response to perceived inadequacies of the biological-constraints approach, some have advocated broadening the range of phenomena to be investigated by students of animal learning (Rozin \& Kalat, 1971; Shettleworth, 1982). Others have called for a cessation of studies of learning in arbitrary laboratory situations and their replacement by efforts to discover the role of behavioral plasticity in the development of adaptive behavior in natural circumstances (Johnston, 1981). While both are surely constructive suggestions, neither broadening of the range of phenomena considered by learning theorists nor greater knowledge of the role of experience in development directly addresses the question of the existence of specialized associative mechanisms.

Study of classic examples of specialized behavioral plasticity to be found in the ethological literature (i.e., song learning, imprinting, navigation, homing, individual recognition) will probably not help answer the question of the existence of specialized associative mechanisms because song learning, imprinting, navigation, homing, and individual recognition may 
not be mediated by associative processes. Studies of the role of experience in behavior development in natural environments may well prove heuristic in suggesting preparations in which to look for specialized associative mechanisms, but whether this approach will be more valuable than others in identifying promising phenomena remains to be seen.

The research program we propose below is not intended as a global strategy for the future of the study of animal learning. Rather, it is suggested as a tactic for addressing a fundamental issue in discussions of animal learning during the past decade. We believe it offers important advantages relative to the biologicalconstraints approach in investigating possible adaptive specializations of associative mechanisms. It provides an orderly program for the discovery of associative phenomena of ecological importance, and it offers promise of adding an ecological dimension to the study of associative learning, compatible with, but not readily assimilated into, current general process theories.

\section{A Comparative Approach to the Study of Association Learning}

Our proposal is to extend to the study of associative learning a research tactic that has proved to be successful in the demonstration and investigation of other types of specialization. In our view, problems to be faced in the study of the adaptive specialization of associative processes are not significantly different from those to be faced in the demonstration of the adaptive specialization of morphological features or instinctive behaviors. Hence, it is appropriate in investigating the adaptive specialization of associative learning to employ research methods that have been successful in solving related problems. Our proposal is thus simply for the introduction of modern comparative methods into the study of animal learning. Brief description of some classic examples from the biological literature should help make explicit differences between the comparative investigations of specialized learning mechanisms we propose and those performed within the framework of the biological constraints approach.

Ground- and cliff-nesting gulls. Of the $\mathbf{4 2}$ species in the gull family (Lauridae), only the kittiwake is exclusively cliff-nesting. The majority of other gull species nest in open terrain. The difficulty experienced by both avian and mammalian predators in attacking kittiwake nests, often located on very narrow ledges on an inaccessible cliff face, is known to result in a lower frequency of predation on both adult kittiwakes and their young than on groundnesting forms (Cullen, 1957). Furthermore, the restricted nest-site area of the kittiwake requires limited movement of flightless kittiwake young. On the hypothesis that the behavior of kittiwakes has become specialized for cliff-nesting, one might expect kittiwakes to exhibit reduced frequencies of those behaviors maintained in ground-nesting gulls by predation pressure and an enhancement of those behaviors that would reduce the probability of movement of juveniles from the nest.

In fact, kittiwake adults alarm-call less frequently, flee less readily from predators, and attack predators far less vigorously than do ground-nesting gulls. Furthermore, adult kittiwakes do not hide the nest site by removing or dispersing egg shells or fecal material from it (Cullen, 1957; Tinbergen, 1963). In general, antipredator behaviors in kittiwakes are impoverished relative to those of ground-nesting gulls. As might further be expected on the hypothesis that the behavior of kittiwakes is specialized for life on cliffs, the young kittiwake is less mobile and less vigorous in its preflight activity than its ground-born relatives (for further examples, see Cullen, 1957).

While the correlation between the exceptional behaviors of kittiwakes and their unique choice of nesting site does not prove that the behaviors in question are specializations for life on cliffs, the argument is a strong one. This strength derives from a series of necessary steps: (1) demonstration of differences in selective pressures acting on cliff- and ground-nesting forms, (2) comparison of the behaviors of taxonomically related species subjected to different pressures, and (3) demonstration of a correlation between behavioral elaboration and known selective pressures.

Additional evidence of the adequacy of the special niche occupied by kittiwakes to explain their unique behavioral traits relative to other gulls is provided by observations of phylogenetically distant but ecologically similar cliff-nesting birds, such as gannets. Gannets share with kittiwakes many of the behaviors that differentiate kittiwakes from ground-nesting gulls (Nelson, 1967). Note that there is no implication of a communality in the physiological or genetic processes responsible for the shared behavior of cliffnesting species. Rather, the claim is that the behavioral communality found in phylogenetically diverse forms reflects convergent responses to similar selective pressures.

Rodents of desert and moist habitat. The extremes of heat and aridity common to many deserts provide severe challenges to their inhabitants. Comparison of the capacity of rodents to survive in the absence of access to free water reveals that desert species (such as the kangaroo rat, Dipodomys merriami) can thrive without access to free water, while nondesert species cannot (Schmidt-Nielsen, 1964).

Support for the hypothesis that the homeostatic behavior of kangaroo rats is different from that of other rodents in consequence of their occupation of arid environments rests on evidence similar to that adduced to support the conclusion that kittiwake behavior has been shaped by life on cliff faces. First, there is an identification of differences in selective 
pressures acting on desert and nondesert forms. Second, a comparison of behaviors (in this case, homeostatic ones) is carried out. And, third, evidence of a correlation between behavioral elaborations and selective pressures is presented. Additional support for the hypothesis that the specialized homeostatic mechanisms of the kangaroo rat are the result of a response to desert conditions is provided by studies indicating that other desert animals, such as camels and Old World desert rodents, employ analogous strategies to avoid dehydration.

It is of relevance to some of the issues discussed below to note that the physiological mechanisms conserving water in desert rodents differ quantitatively, and not qualitatively, from similar processes in species indigenous to moist habitats. Kangaroo rats do not survive in arid regions by storing free water in their bodies (as camels were alleged to do in their humps), by absorbing atmospheric moisture, by internally storing waste products, or by any other processes unknown in their non-desert-dwelling relatives. Rather, they exhibit quantitative differences from other rodents in the mechanisms they employ to reduce water loss. There is, thus, no implication that adaptive specialization implies the evolution of qualitatively unique processes in the specialist.

Comparative studies of learning. The comparative approach to the study of learning we advocate differs from that traditionally employed in studies of animal learning. Traditionally, comparative studies of learning have been conducted to test the generality of learning phenomena and processes. Given this goal, the learning of highly dissimilar species, such as goldfish, turtles, rats, and pigeons (e.g., Bitterman, 1975) or rats and large herbivores (Zahorik \& Houpt, 1977, 1981), have been compared. Such comparisons provide important information about the generality of learning phenomena, or the lack thereof. However, they do not help integrate the study of animal learning with biological considerations, because differences in learning observed among highly disparate species cannot be easily related to particular biological variables. In such investigations, the species selected for comparison were not sufficiently closely related phylogenetically to permit attribution of any observed differences in behavior to differences in ecological pressures. In addition, differences in the ecology of the various species were too extreme to allow specification of meaningful dimensions for comparison.

A step in the proposed direction has been taken by Cole, Hainsworth, Kamil, Mercier, and Wolf (1982) in their study of foraging strategies of nectar-feeding birds. Cole et al. argued that in the natural environment, a hummingbird returning to a flower from which it had previously fed would have a lower rate of net energy gain than a conspecific exhibiting a tendency to avoid blossoms from which it had recently extracted nectar. Hence, one might predict a predisposition in hummingbirds to learn a "winshift" strategy more easily than a "win-stay" strategy in a laboratory learning task using food as the reinforcer. Observation of this predicted outcome in three species of hummingbird was taken as evidence that an evolutionary history of food resource distribution in space and time exerts important influences on the predisposition of hummingbirds to learn a "win-shift" strategy. While the data are certainly consistent with such a hypothesis, they do not provide very strong support for it. Consider, for example, the finding of Olton and Schlosberg (1978) that Norway rats, like hummingbirds, acquire a "win-shift" strategy for food reward more readily than a "win-stay" strategy. One would be hard pressed to argue that food sources exploited by rats in nature have temporal and spatial distributions similar to food sources exploited by hummingbirds.

To establish that some associative learning capacity of nectar-feeding birds is the result of ecological pressures, what is needed is comparison of learned foraging strategies in nectar-feeding birds and nonnectar-feeding birds of close phylogenetic relationship, and demonstration of a correlation between learning predispositions and ecological pressures. Demonstration of a preference for "win-shift" over "win-stay" strategies in nectar-feeding honey creepers (Kamil, 1978), sunbirds (Gill \& Wolf, 1977), and hummingbirds (Cole et al., 1982) may or may not be an example of convergence to exploit slowly replenished food sources. Until a preference for "win-stay" over "win-shift" strategies is demonstrated in related species exploiting nondepletable resources, the preference for "win-shift" in nectarfeeding birds only suggests that such a preference is a specialization. Furthermore, even if one were to find a difference in the ease of learning of "win-stay" and "win-shift" strategies in closely related species exploiting different types of food sources, this would only be an important first step in an investigation of the behavioral mechanisms underlying the difference. Traditional analyses of the causes of the difference would be required even if the function of the difference was well established. It is possible, for example, that learning of "win-stay" and "win-shift" strategies proceeds at the same rate against different baseline tendencies for spontaneous alternation.

Daly, Rauschenberger, and Behrends (1982) recently completed a study that is more closely in line with our proposals. Two species of kangaroo rat (Dipodomys) that varied in their degree of dietary specialization were compared in a series of foodaversion learning studies. It was predicted that learning of aversions to a novel food paired with toxicosis would be more rapid in the generalist than in the 
specialist feeder. Although the results failed to offer strong support for the hypothesis, the logic of the experiment is fully in accord with what we suggest.

As is clear from the above, the tactic we propose is a conservative one involving (1) observation of related species in natural circumstances to identify differences in selective pressures acting on those species, (2) framing of hypotheses concerning anticipated differences in associative processes between species as a consequence of observed differences in selection pressures acting on them, and (3) conduct of appropriate experiments under controlled conditions to test these hypotheses. Steps 1 and 2, taken together, are intended to circumvent the post hoc nature of many present discussions of adaptive specializations and biological constraints. Steps 1 and 3 are intended to permit an orderly synthesis of ecological and learning paradigms. Our emphasis is on studies comparing learning phenomena in species close in phylogeny, but disparate in ecology. The alternative strategy of comparing the learning capacity of phylogenetically distant species facing common problems is secondary and supportive in providing information about behavioral adaptations to particular ecological circumstances.

\section{Comparisons with Other Biological Approaches to the Study of Learning}

The modern comparative approach we have described contrasts with biological constraint approaches to the study of learning in emphasizing the importance of species comparisons. Past studies of biological constraints on learning have often dealt with differences in how members of a single species learn different things, such as scrabbling, open rearing, digging, and face washing to obtain food reward (Shettleworth, 1975). Some prominent differences in learning between species were discussed. For example, Wilcoxon, Dragoin, and Kral (1971) reported that quail are more likely to learn aversions to visual than to taste properties of water, whereas rats are more likely to learn aversions to taste cues than to visual ones. However, identification of differences in selective pressures between species was by appeal to argument rather than by appeal to experimental evidence, and no attempt was made to identify the behavioral processes underlying species differences in behavior. As might be expected, subsequent research has cast doubt on the adequacy of ecological factors or unique learning mechanisms to account for the observed species differences (Gillette, Martin, \& Bellingham, 1980; Lett, 1980).

A comparative approach concerned with ecological adaptation is in some ways similar to the adaptive specializations approach advocated by Rozin and Kalat (1971). Both deal with the adaptive value of various forms of learning. However, the comparative approach provides clearer guidelines for future re- search and is more explicit about integrating studies of learning with ecological considerations. The adaptive specializations approach does not specify where or how one might search for new instances of specialization. Furthermore, as discussed by Rozin and Kalat (1971), the approach seems to end with the demonstration that certain forms of learning are specialized adaptations. In contrast, the comparative approach requires a more comprehensive and interdisciplinary research program. It specifies that to search for principles of adaptation using the comparative approach, one has to compare the performance of taxonomically similar but ecologically disparate species in learning situations. In conducting such a comparison, one has to identify the relevant ecological differences between species in advance and then strive to relate observed differences in learning to these ecological factors. Thus, the comparative approach permits testing predictions about adaptive function.

The approach under discussion also avoids the problem of confusing functional approaches to the study of learning with studies of learning mechanisms. One strength of the research strategy we advocate is that it allows identification of adaptive specializations of learning. Once a specialization is identified, one can profitably ask, using traditional techniques for the study of learning phenomena, whether the specialized capacity for behavior acquisition is the result of minor modifications of a known learning process, variations in some process other than learning, or a unique learning mechanism.

The comparative approach we are suggesting may also be contrasted with the ecological approach to the study of learning proposed by Johnston (1981; see also Johnston \& Turvey, 1980). Johnston advocates abandoning previous frameworks for the study of learning and starting the enterprise anew with descriptions of naturally occurring instances of learning. The identification of what animals learn in natural habitats is to be followed by analyses of how they learn. Such analyses are assumed to provide local principles of adaptation, from which more global principles may be formulated by generalization. Our comparative approach is a less revolutionary proposal. It does not seek to replace studies of general process learning theory. Rather, it seeks to supplement them and better integrate them with ecological considerations.

Laboratory investigations of general process learning theory have demonstrated that numerous learning phenomena observed in rats and pigeons also occur in such diverse animals as the terrestrial slug (Sahley, Rudy, \& Gelperin, 1981) and the honeybee (Couvillon \& Bitterman, 1980, 1982). Such impressive similarities in learning in widely divergent species offer strong support for a general process approach. Abandoning the general process approach in at- 
tempts to better integrate the study of learning with biological considerations would be reckless. Carefully designed comparative investigations of learning can add a biological dimension and help integrate the study of learning with behavioral ecology and phylogeny without rejecting the general process tradition.

\section{REFERENCES}

AdAms, J. A. Learning and memory: An introduction. Homewood, Ill: Dorsey, 1976.

Annable, A., \& Wearden, J. H. Grooming movements as operants in the rat. Journal of the Experimental Analysis of Behavior, 1979, 32, 297-304.

Bitterman, M. E. The comparative analysis of learning. Science, 1975, 188, 699-709.

Bolles, R. C. Species-specific defense reactions and avoidance learning. Psychological Review, 1970, 77, 32-48.

Bolles, R. C. Learning theory. New York: Holt, Rinehart \& Winston, 1975.

Breland, K., \& Breland, M. The misbehavior of organisms. American Psychologist, 1961, 16, 681-684.

Cole, S., Hainsworth, F. R., Kamil, A. C., Mercier, T., \& WoLF, L. L. Spatial learning as an adaptation in hummingbirds. Science, 1982, $217,655-657$.

Couvillon, P. A., \& Bitterman, M. E. Some phenomena of associative learning in honeybees. Journal of Comparative and Physiological Psychology, 1980, 94, 878-885.

Couvillon, P. A., \& Bitte rman, M. E. Compound conditioning in honeybees. Journal of Comparative and Physiological Psychology, 1982, 96, 192-199.

Crawrord, M., \& Masterson, F. Components of the flight response can reinforce bar-press avoidance learning. Journal of Experimental Psychology: Animal Behavior Processes, 1978, 4, 144-151.

Cullen, E. Adaptations in the kittiwake to cliff-nesting. Ibis, $1957,99,275-302$.

Daly, M., Rauschenberger, J., \& Behrends, P. Food aversion learning in kangaroo rats: A specialist-generalist comparison. Animal Learning \& Behavior, 1982, 10, 314-320.

D'Amato, M. R.; \& Buckiewicz, J. Long-delay, one-trial conditioned preference and retention in monkeys (Cebus apella). Animal Learning \& Behavior, 1980, 8, 359-362.

D'Amato, M. R., \& Safaruan, W. R. Differential effects of delay of reinforcement on acquisition of affective and instrumental responses. Animal Learning \& Behavior, 1981, 9, 209-215.

Dickinson, A. Contemporary animal learning. Cambridge, England: Cambridge University Press, 1980.

DomJan, M. Ingestional aversion learning: Unique and general processes. In J. S. Rosenblatt, R. A. Hinde, C. Beer, \& M.-C. Busnel (Eds.), Advances in the study of behavior (Vol. 11). New York: Academic Press, 1980.

Domjan, M. Biological constraints on instrumental and classical conditioning 10 years later: Implications for general process theory. In G. H. Bower (Ed.), The psychology of learning and motivation (Vol. 17). New York: Academic Press, 1983.

Garcia, J., Ervin, F. R., \& Koelling, R. A. Learning with prolonged delay of reinforcement. Psychonomic Science, 1966, 5, 121-122.

Garcia, J., \& Koelling, R. A. Relation of cue to consequence in avoidance learning. Psychonomic Science, 1966, 4, 123-124.

GiLL, F. B., \& WoLF, L. L. Nonrandom foraging by sunbirds in a patchy environment. Ecology, 1977, 58, 1284-1296.

Gillette, K., Martin, G. M., \& Bellingham, W. P. Differential use of food and water cues in the formation of conditioned aversions by domestic chicks (Gallus gallus). Journal of Experimental Psychology: Animal Behavior Processes, 1980, 6, 99-111.
Hall, J. F. Classical conditioning and instrumental learning: $A$ contemporary approach. New York: J. B. Lippincott, 1976.

Hinde, R. A. Constraints on learning: An introduction to the problem. In R. A. Hinde \& J. Stevenson-Hinde (Eds.), Constraints on learning. London: Academic Press, 1973.

Hinde, R. A., \& Stevenson-Hinde, J. (Eds.). Constraints on learning. London: Academic Press, 1973.

HoLtts, K. L. Pavlovian conditioning of signal-centered action patterns and autonomic behavior: $A$ biological analysis of function. In J. S. Rosenblatt, R. A. Hinde, C. Beer, \& M.-C. Busnel (Eds.), Advances in the study of behavior (Vol. 12). New York: Academic Press, 1982

Houston, J. P. Fundamentals of learning. New York: Academic Press, 1976.

JACOBS, W. J., \& LoLoRdo, V. M. The sensory basis of avoidance responding in the rat. Learning and Motivation, 1977, 8, 448-466.

JAcoss, W. J., \& LoLordo, V. M. Constraints on Pavlovian aversive conditioning: Implications for avoidance learning in the rat. Learning and Motivation, 1980, 11, 427-455.

Johnston, T. D. Contrasting approaches to a theory of learning. Behavioral and Brain Sciences, 1981, 4, 125-173.

Johnston, T. D., \& TURveY, M. T. A sketch of an ecological metatheory for theories of learning. In G. H. Bower (Ed.), The psychology of learning and motivation (Vol. 14). New York: Academic Press, 1980.

KamiL, A. C. Systematic foraging by a nectar-feeding bird, the amakihi (Loxops virens). Journal of Comparative and Physiological Psychology, 1978, 92, 388-396.

Krane, R. V., \& Whaner, A. R. Taste aversion learning with a delayed shock US: Implications for the "generality of the laws of learning." Journal of Comparative and Physiological Psychology, 1975, 88, 882-889.

Lehrman, D. S. Semantic and conceptual issues in the naturenurture problem. In L. R. Aronson, E. Tobach, D. S. Lehrman, \& J. S. Rosenblatt (Eds.), Development and evolution of behavior. San Francisco: Freeman, 1970.

LETT, B. $T$. Long delay learning in the $T$ maze. Learning and Motivation, 1975, 6, 80-90.

LETT, B. T. Taste potentiates color-sickness associations in pigeons and quail. Animal Learning \& Behavior, 1980, 8, 193-198.

Lieberman, D. A., McIntosh, D. C., \& Thomas, G. V. Learning when reward is delayed: A marking hypothesis. Journal of Experimental Psychology: Animal Behavior Processes, 1979, 5, 224-242.

Logue, A. W. Taste aversion and the generality of the laws of learning. Psychological Bulletin, 1979, 86, 276-296.

LoLordo, V. M. Selective associations. In A. Dickinson \& R. A. Boaks (Eds.), Mechanisms of learning and motivation. Hillsdale, N.J: Erlbaum, 1979.

Mackintosh, N. J. A theory of attention: Variations in the associability of stimuli with reinforcement. Psychological Review, 1975, 82, 276-298.

Morgan, C. T., \& King, R. A. Introduction to psychology. New York: McGraw-Hill, 1975.

Morgan, M. J., \& Nicholas, D. J. Discrimination between reinforced action patterns in the rat. Learning and Motivation, 1979, 10, 1-22.

Nezson, J. B. Colonial and cliff nesting in the gannet. Ardea, $1967,55,60-90$.

Olton, D. S., \& Schlosbera, P. Food-searching strategies in young rats: Win-shift predominates over win-stay. Journal of Comparative and Physiological Psychology, 1978, 92, 609-618.

Pearce, J. M., Colwill, R. M., \& Hall, G. Instrumental conditioning of scratching in the laboratory rat. Learning and Motivation, $1978,9,255-271$.

Pearce, J. M., \& Hall, G. A model for Pavlovian learning: Variations in the effectiveness of conditioned but not unconditioned stimuli. Psychological Review, 1980, 87, 532-552.

Pearce, J. M., Nicholas, D. J., \& Dickinson, A. The potentiation effect during serial conditioning. Quarterly Journal of Experimental Psychology, 1981, 33B, 159-179. 
Rachlin, H. Behavior and learning. San Francisco: Freeman, 1976.

Rachlin, H., Battalio, R., Kagel, J., \& Green, L. Maximization theory in behavioral psychology. Behavioral and Brain Sciences, 1981, 4, 371-417.

Rescorla, R. A., \& Furrow, D. R. Stimulus similarity as a determinant of Pavlovian conditioning. Journal of Experimental Psychology: Animal Behavior Processes, 1977, 3, 203-215.

Rescorla, R. A., \& Gillan, D. G. An analysis of the facilitative effect of similarity on second-order conditioning. Journal of Experimental Psychology: Animal Behavior Processes, 1980, 6, 339-351.

Rescorla, R. A., \& Holland, P. C. Some behavioral approaches to the study of learning. In M. R. Rosenzweig \& E. L. Bennett (Eds.), Neural mechanisms of learning and memory. Cambridge, M.I.T. Press, 1976.

Rescorla, R. A., \& Holland, P. C. Behavioral studies of associative learning in animals. Annual Review of Psychology, 1982, 33, 265-308.

REvUsky, S. The role of interference in association over a delay. In W. K. Honig \& P. H. R. James (Eds.), Animal memory. New York: Academic Press, 1971.

Rozin, P., \& Kalat, J. W. Specific hungers and poison avoidance as adaptive specializations of learning. Psychological Review, $1971,78,459-486$.

Sahrey, C., Rudy, J. W., \& Gelperin, A. An analysis of associative learning in a terrestrial mollusc. I. Higher-order conditioning blocking, and a transient US-pre-exposure effect. Journal of Comparative Physiology-A, 1981, 144, 1-8.

Schmidt-Nielson, K. Desert animals. Oxford: Clarendon, 1964.

Schwartz, B. Psychology of learning and behavior. New York: Norton, 1978.

Seligman, M. E. P. On the generality of the laws of learning. Psychological Review, 1970, 77, 406-418.

Seligman, M. E. P., \& Hager, J. L. (Eds.), Biological boundaries of learning. New York: Appleton-Century-Crofts, 1972.

ShetTleworth, S. J. Constraints on learning. In D. S. Lehrman, R. A. Hinde, \& E. Shaw (Eds.), Advances in the study of behavior (Vol. 4). New York: Academic Press, 1972.

Shetrleworth, S. J. Reinforcement and the organization of behavior in golden hamsters: Hunger, environment, and food reinforcement. Journal of Experimental Psychology: Animal Behavior Processes, 1975, 1, 56-87.

She Ttreworth, S. J. Reinforcement and the organization of behavior in golden hamsters: Punishment of three action patterns. Learning and Motivation, 1978, 9, 99-123.
Shettheworth, S. J. Function and mechanism in learning. In $\mathbf{M}$. Zeiler \& P. H. Harzem (Eds.), Advances in analysis of behavior (Vol. 3). New York: Wiley, 1982.

SPIKER, V. Taste-aversion: A procedural analysis and an alternative paradigmatic classification. Psychological Record, $1977,27,753-769$.

TARPY, R. M., \& MAYER, R. E. Foundations of learning and memory. Glenview, Ill: Scott, Foresman, 1978.

TEsta, T. J. Effects of similarity of location and temporal intensity pattern of conditioned and unconditioned stimuli on the acquisition of conditioned suppression in rats. Journal of Experimental Psychology: Animal Behavior Processes, 1975, 1, 114-121.

Testa, T. J., \& Ternes, J. W. Specificity of conditioning mechanisms in the modification of food preferences. In $L$. M. Barker, M. R. Best, M. Domjan (Eds.), Learning mechanisms in food selection. Waco, Tex: Baylor University Press, 1977.

Timberlake, W., Wahl, G., \& King, D. Stimulus and response contingencies in the misbehavior of rats. Journal of Experimental Psychology: Animal Behavior Processes, 1982, 8, 62-85.

Tinbengen, N. On aims and methods of ethology. Zeitschrift für Tierpsychologie, 1963, 20, 410-433.

WAGNER, A. R. SOP: A model of automatic memory processing in animal behavior. In N. E. Spear \& R. R. Miller (Eds.), Information processing in animals. Hillsdale, N.J: Erlbaum, 1982.

Welker, R. J., \& Wheatley, K. L. Differential acquisition of conditioned suppression in rats with increased and decreased luminance levels as CS+s. Learning and Motivation, 1977, 8, 247-262.

Wilcoxon, H. C., Dragoin, W. B., \& Kral, P. A. Illnessinduced aversions in rat and quail: Relative salience of visual and gustatory cues. Science, 1971, 171, 826-828.

ZaHORIK, D. M., \& HoUPT, K. A. The concept of nutritional wisdom: Applicability of laboratory learning models to large herbivores. In L. M. Barker, M. R. Best, \& M. Domjan (Eds.), Learning mechanisms in food selection. Waco, Tex: Baylor University Press, 1977.

Zahorik, D. M., \& Houpt, K. A. Species differences in feeding strategies, food hazards, and the ability to learn food aversions. In A. C. Kamil \& T. D. Sargent (Eds.), Foraging behavior. New York: Garland STPM Press, 1981.

(Manuscript received September 27, 1982; revision accepted for publication February 24, 1983.) 